University of Wollongong

Research Online

Faculty of Engineering and Information

Faculty of Engineering and Information

Sciences - Papers: Part A

Sciences

$1-1-2012$

\title{
Distributed energy storage for mitigation of voltage-rise impact caused by rooftop solar PV
}

M J. E Alam

University of Wollongong, mjea982@uowmail.edu.au

K M. Muttaqi

University of Wollongong, kashem@uow.edu.au

Darmawan Sutanto

University of Wollongong, soetanto@uow.edu.au

Follow this and additional works at: https://ro.uow.edu.au/eispapers

Part of the Engineering Commons, and the Science and Technology Studies Commons

Research Online is the open access institutional repository for the University of Wollongong. For further information contact the UOW Library: research-pubs@uow.edu.au 


\title{
Distributed energy storage for mitigation of voltage-rise impact caused by rooftop solar PV
}

\begin{abstract}
A high penetration of solar photovoltaic (PV) resources into distribution networks may create voltage rise problem when the generation from PV resources substantially exceeds the load demand. To reduce the voltage rise, the excess amount of power from the solar PV units needs to be reduced. In this paper, distributed storage systems are proposed for the mitigation of voltage rise problem. The surplus energy from the solar PV is used to charge the distributed storage units during midday, when the power from the solar PV would be typically higher than the load level. This stored energy is then used to reduce the peak load in the evening. An intelligent strategy for charging and discharging control to make effective use of the storage capacity is discussed. The proposed voltage rise mitigation strategy is verified on a practical low voltage distribution feeder in Australia. (C) 2012 IEEE.
\end{abstract}

\section{Keywords}

distributed, energy, storage, mitigation, solar, voltage, pv, rise, impact, caused, rooftop

Disciplines

Engineering | Science and Technology Studies

\section{Publication Details}

M. J. E. Alam, K. M. Muttaqi \& D. Sutanto, "Distributed energy storage for mitigation of voltage-rise impact caused by rooftop solar PV," in IEEE Power and Energy Society General Meeting, 2012, pp. 1-8. 


\title{
Distributed Energy Storage for Mitigation of Voltage-rise Impact caused by Rooftop Solar PV
}

\author{
M. J. E. Alam, Grad. Student Member, IEEE, K. M. Muttaqi, Senior Member, IEEE and D. Sutanto, \\ Senior Member, IEEE
}

\begin{abstract}
A high penetration of solar photovoltaic (PV) resources into distribution networks may create voltage rise problem when the generation from PV resources substantially exceeds the load demand. To reduce the voltage rise, the excess amount of power from the solar PV units needs to be reduced. In this paper, distributed storage systems are proposed for the mitigation of voltage rise problem. The surplus energy from the solar PV is used to charge the distributed storage units during midday, when the power from the solar PV would be typically higher than the load level. This stored energy is then used to reduce the peak load in the evening. An intelligent strategy for charging and discharging control to make effective use of the storage capacity is discussed. The proposed voltage rise mitigation strategy is verified on a practical low voltage distribution feeder in Australia.
\end{abstract}

Index Terms-Voltage rise, solar photovoltaic resources, distributed storage, low voltage distribution network.

\section{INTRODUCTION}

$\mathrm{S}$ OLAR photovoltaic (PV) resources are the most commonly observed form of distributed generation at the residential customer premises in low voltage (LV) distribution networks. Depending on their capacity, the rooftop solar PV units share the proportions of loads connected at the $\mathrm{AC}$ mains of residential households. Serving part of the loads locally by PV resources help to reduce stress on the distribution feeder and can improve system performance by reducing feeder loss and releasing system capacity. At the same time, integration of $\mathrm{PV}$ resources at a high penetration level can impose several challenges for distribution network operators. Voltage rise problem has been reported as one of those major concerns [13].

Without PV resources installed, voltage along distribution feeders would typically drop from the substation to the remote end due to line impedances and loads. With integration of PV generation, voltage profile improves as voltage drop across feeder segments reduces due to reduced power flow through the feeder. However, if the generation from PV is greater than the local demand at the point of common coupling (PCC) of the PV inverter, the surplus power flows back to the grid. The excess power from PV inverters may produce reverse power

This work is supported by the Australian Research Council (ARC) and Essential Energy Linkage Grant, LP100100618

M. J. E. Alam, K. M. Muttaqi and D. Sutanto is with Endeavour Energy Power Quality and Reliability Center, School of Electrical Computer an Telecommunications Engineering, University of Wollongong, NSW 2522, Australia (e-mail: mjea982@uowmail.edu.au, kashem@uow.edu.au, soetanto@uow.edu.au). flows in the feeder that would create voltage rise at the feeder. Typical peak time of the solar PV resources is noon when sun irradiance level is the highest. Household demand on the other hand is typically lower at this time of the day. LV distribution feeder may therefore experience voltage rise resulting from light load and peak PV generation at this time. However, distribution utilities need to operate the feeders without violating the voltage limits stipulated by the local standards. With high penetration of PV resources at LV level, there is a possibility of violation of upper limit voltage. Solutions need to be proposed to reduce the overvoltage problem caused by PV so that the targeted penetration level can be achieved while compliance with the system operation limits is also preserved.

Authors in [4] have proposed active power curtailment and reactive power absorption for voltage rise reduction. Active power curtailment may not be an attractive solution from economic point of view; reactive power absorption may create high reactive power flow over the network, especially for networks with high $\mathrm{R} / \mathrm{X}$ ratio. It would also incur additional loss in the feeder due to high current flow [5]. Authors in [6] have also proposed reactive power based voltage control technique to mitigate voltage rise and also discussed the limitation of their technique. Application of storage devices integrated with residential PV systems was proposed in [7] to store the surplus power from the PV array during noon time. The main purpose of this work [7] was to reduce the power loss caused by not being able to use the generated power from PV. Battery storage can store this unused energy locally for use in the evening peak load period. This operation can also reduce the voltage rise problem during peak PV generation by injecting less power to the grid and storing the excess energy in the battery storage while supporting the voltage during evening peak by serving the local loads from the battery storage and hence reducing stress on the grid.

This paper will present the application of battery energy storage devices to reduce the voltage rise problem in a PV solar installation. Improvement of voltage profile during evening peak by using stored energy to serve local loads will also be discussed. Modeling of storage devices and its application in voltage rise mitigation will be presented in the context of Australian electricity distribution networks.

\section{The Voltage Rise Problem}

Voltage rise produced by solar PV resources in a distribution feeder is a result of offsetting the loads in the feeder by PV generation. Without PV, voltage would drop 
along the feeder as shown in Fig. 1(b) for a simple redial feeder shown in Fig. 1 (a). With PV, if all loads are perfectly balanced by PV generations at each point of connection, then ideally no active power would flow through the feeder and voltage profile would be nearly flat as in Fig. 1(c). However, if the PV generation exceeds feeder loads, especially at furthest end of the feeder, then power flows back from feeder to the upstream network and this causes the voltage to rise, as shown in Fig. 1(d). In this scenario,, voltage rise occurs due to the surplus power at the PCC of each PV connection.

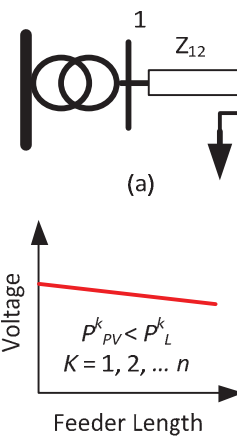

(b)

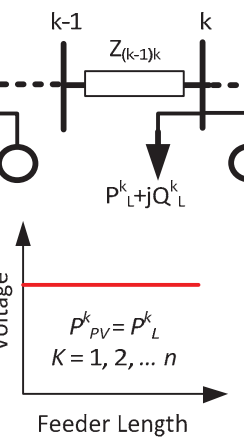

(c)

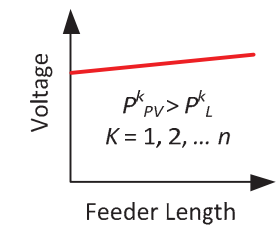

(d)
Fig. 1. Voltage profile along feeder with different PV generation (a) single line diagram of feeder (b) voltage drop (c) flat voltage profile (d) voltage rise

For the simple system shown in Fig. 1, if the PV unit connected at $k$-th node produces $P_{P V}^{k}$ amount of real power and the load connected at this node is $P^{k}{ }_{L}+j Q^{k}{ }_{L}$, then the net active power injection into the grid, $\left(P_{P V}^{k}-P_{L}^{k}\right)$, can be negative, zero or positive depending on the amount of $\mathrm{PV}$ generation. A four quadrant P-Q diagram presented in Fig. 2, can be used to illustrate this situation.

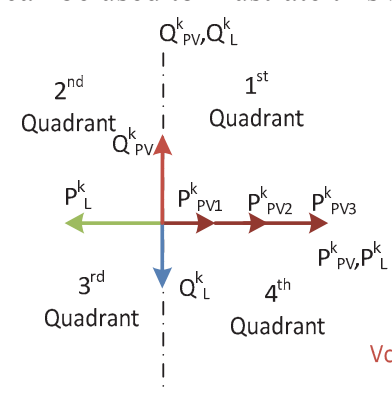

(a)

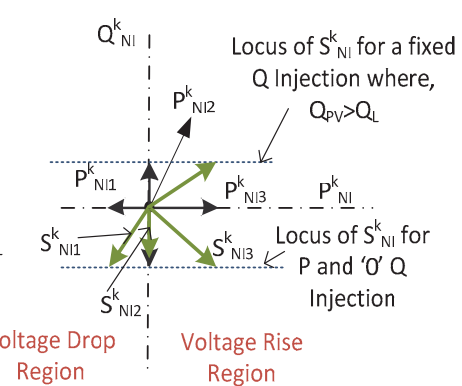

(b)
Fig. 2. Four quadrant net power injection diagram (a) load and PV power injection (b) net power injection at PCC

From the perspective of power injection, loads are shown in the negative $\mathrm{P}$ and $\mathrm{Q}$ axes and power injections from $\mathrm{PV}$ are shown in the positive $\mathrm{P}$ and $\mathrm{Q}$ axes in Fig. 2(a). The net injection at this $k$-th node can be obtained as,

$$
S_{N I}^{k}=P_{N I}^{k}+j Q_{N I}^{k}=\left(P_{P V}^{k}-P_{L}^{k}\right)+j\left(Q_{P V}^{k}-Q_{L}^{k}\right)
$$

For a PV connection where $P_{P V 1}^{k}<P_{L,}^{k}$ the net $P$ injection, $\mathrm{P}^{\mathrm{k}}{ }_{\mathrm{NI} 1}$ is negative as shown in Fig. 2(b); with increasing level of $P_{P V}^{k}$ the net $P$ injection reaches zero when $P_{P V}^{k}=P_{L}^{k}$ and eventually becomes positive when $P_{P V 1}^{k}>P_{L}^{k}$. If the $Q$ injection from $\mathrm{PV}$ inverter is zero (unity power factor operation), then the net $Q$ injection always remains negative and the locus of net apparent power injection, $S_{N I}^{k}$ from the PV inverter is a straight line parallel to the $P$ axis intersecting the
$Q$ axis at $-Q_{L}^{k}$. With increasing $P_{P V}^{k}$, the operation of $k$-th node changes position from $3^{\text {rd }}$ to $4^{\text {th }}$ quadrant. If the PV inverter injects $Q$ such that $Q_{P V}^{k}>Q_{L}^{k}$, then the operation shifts to $1^{\text {st }}$ quadrant where the both net $P$ injection and net $Q$ injection are positive. This study will only consider unity power factor (UPF) operation of rooftop PV units and the operation will be limited to $3^{\text {rd }}$ and $4^{\text {th }}$ quadrant.

Ideally, the voltage rise problem would start to appear with transition of the net injection from $3^{\text {rd }}$ to $4^{\text {th }}$ quadrant, which means the generation from solar PV is exceeding the load level at the PCC. Reduction of voltage rise would therefore involve deploying a mechanism to block or reduce the surplus power from entering into the grid. Integration of storage devices with residential PV systems could play a role in this situation by using the surplus energy of PV generation to charge the battery and discharge it at some later stage when PV resources are unavailable or delivering low power. The amount of reduction of voltage rise at a given time instant will depend on the amount of power diverted to charge the battery and this depends on various factors including battery capacity, charging rate, charging method etc. Modeling of storage devices and its application in voltage rise mitigation will be discussed in the following section.

\section{Application of Distributed Storage to Mitigate VOLTAGE RISE IMPACT}

As shown in Fig. 2, the voltage rise situation would take place when the net injection is at the $4^{\text {th }}$ quadrant. The storage device will reduce the net active power injection to a lower level so that the operating point becomes closer to the negative $\mathrm{Q}$ axis in the $4^{\text {th }}$ quadrant as shown in Fig. 3(a) and (b).

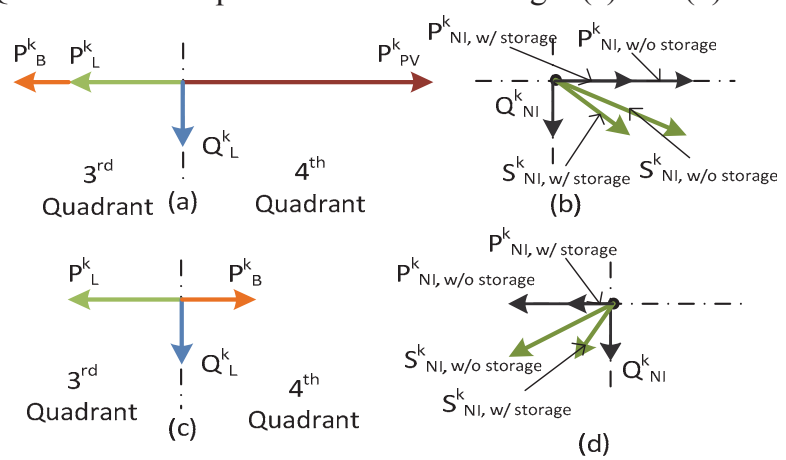

Fig. 3. Four quadrant net power injection diagram with storage (a) and (b) charging operation, (c) and (d) discharge operation

In the heavy load period during evening, without the storage device, the net injection would be in the $3^{\text {rd }}$ quadrant, whereas with storage it would be shifted in the right direction towards the $4^{\text {th }}$ quadrant, as in Fig. $4(\mathrm{c})$ and (d).

The capability of the storage devices to influence the net power injection and its application to voltage rise mitigation and voltage support will be discussed in the following subsections.

\section{A. Solar PV Model}

Rooftop PV installations at LV customer premises mainly consist of the solar PV modules that produce the DC power 
from solar insolation, and a power conditioning unit that accomplishes multiple functions including maximum power point tracking, DC-AC conversion and filtering. Ambient temperature and sun insolation level influence the currentvoltage (I-V) characteristics of the PV modules. Variation of these parameters can change the solar power output. The DC current produced by the solar PV module, $I_{d c}$ is given by [8],

$$
I_{d c}=f\left(I_{d c}, V_{d c}\right)=I_{p v}-I_{0}\left(e^{A}-1\right)-B
$$

In (2), $A=\frac{V_{d c}+I_{d c} R_{s}}{a V_{t}}$, and $B=\frac{V_{d c}+I_{d c} R_{s}}{R_{p}}$

where: $I_{p v}$ is the PV current,

$I_{0}$ is the diode current,

$V_{t}$ is the thermal voltage,

$a$ is the diode ideality factor,

$R_{s}$ is the module series resistance and

$R_{p}$ is the parallel resistance.

Numerical method will be applied to solve the transcendental expression in (2) to find the values of $R_{s}$ and $R_{p}$ at Standard Test Conditions (STC) [9]. These parameters will then be applied to obtain the I-V characteristic of the modules at different ambient temperatures and sun insolation levels. The method used for modeling the I-V characteristics of the PV module discussed in [8] will be applied in this paper.

The first step is to fit the I-V characteristic in (2) for Standard Test Conditions (STC) by obtaining $\mathrm{R}_{\mathrm{s}}$ and $\mathrm{R}_{\mathrm{p}} \mathrm{using}$ iterative technique. In the first iteration, short circuit current at STC, $I_{S c, S T C}$ provided by the manufacturer will be used to find out the initial value of the photovoltaic current at STC using (4).

$$
I_{p v, S T C}=I_{s c, S T C} \frac{R_{p}+R_{s}}{R_{p}}
$$

where, the initial assumptions of $\mathrm{R}_{\mathrm{s}}$ is zero and the initial value of $R_{p}$ is estimated using (5).

$$
R_{p}=\frac{V_{m p p, S T C}}{I_{s c, S T C}-I_{m p p, S T C}}-\frac{V_{o c, S T C}-V_{m p p, S T C}}{I_{m p p, S T C}}
$$

where: $V_{m p p, S T C}$ is the module voltage at maximum power point,

$V_{O c, S T C}$, the module voltage at open circuit and

$I_{m p p, S T C}$ the module current at maximum power point, all at STC.

All of these parameters are available from manufacturer data Diode current $I_{0}$ at STC can be obtained from the expression (6).

$$
I_{0, S T C}=\frac{I_{s c, S T C}}{\exp \left(\frac{V_{o c, S T C}}{a V_{t}}\right)-1}
$$

With the values of the parameters obtained by (4)-(6), I-V characteristic represented by (2) is solved for $I_{d c}$ for a range of $V_{d c}$ values, $\left\{0, V_{o c, S T C}\right\}$. The maximum calculated power, according to the model, is obtained by determining the maximum value from $\left(V_{d c} \times I_{d c}\right)$. Iterations will be continued until the absolute difference between this calculated maximum power and manufacturer provided maximum power becomes less than a tolerance value in the order of $1 \times 10^{-4}$.

After the first iteration, $\mathrm{R}_{\mathrm{s}}$ will be incremented slowly and the value of $R_{p}$ will be obtained using (7).

$$
R_{p}=\frac{V_{m p p, S T C}\left(V_{m p p, S T C}+I_{m p p, S T C} R_{s}\right)}{V_{m p p, S T C} I_{p v, S T C}-V_{m p p, S T C} I_{0, S T C}\left(e^{A}-1\right)-P_{m p p, S T C}}
$$

Once the values of $R_{s}$ and $R_{p}$ are found to fit the manufacturer supplied I-V characteristic at STC, the I-V and $\mathrm{P}-\mathrm{V}$ characteristics at any given ambient temperature and insolation can be obtained using the following procedures.

The diode current at any given temperature can be obtained from (8),

where, $\quad C=\frac{V_{o c, S T C}+K_{V} \Delta T}{a V_{t}}$

where: $K_{I}$ is the temperature to current coefficient,

$K_{V}$ is the voltage to temperature coefficient, and

$\Delta T$ is the difference between the given absolute cell operating temperature $\left({ }^{\circ} \mathrm{K}\right)$ from STC temperature.

The absolute cell operating temperature, $T_{\text {cell }}$, can be obtained from the ambient temperature, $t_{a m b}$, using (10).

$$
T_{\text {cell }}=273+t_{\text {amb }}+\left(\frac{N O C T-20}{0.8}\right)
$$

where, NOCT is the Nominal Cell Operating Temperature, defined as the cell operating temperature at $20^{\circ}$ and 0.8 sun insiolation.

The short circuit current and the PV current at any temperature and the sun insolation level can be obtained by,

$$
\begin{aligned}
& I_{s c}=I_{s c, S T C}\left(1+K_{I} \Delta T\right) S \\
& I_{p v}=I_{p v, S T C}\left(1+K_{I} \Delta T\right) S
\end{aligned}
$$

where: $S$ is the ratio of ambient insolation level to the insolation level at STC.

Using the parameter values obtained by (8)-(11), (2) will be solved again for $\mathrm{I}_{\mathrm{dc}}$ for a range of $\mathrm{V}_{\mathrm{dc}}$ values within $\left\{0, V_{o c}\right\}$. This will produce the $\mathrm{I}-\mathrm{V}$ characteristic at the given temperature and insolation level; the $\mathrm{P}-\mathrm{V}$ characteristic will be obtained by multiplying $I_{d c}$ and $V_{d c}$ and the maximum power point will be determined. The DC power thus obtained at the ambient condition will be converted to the AC power using the inverter. Inverter efficiency $\eta_{i n v}$, PV module mismatch factor $\eta_{m m}$ and dirt factor, $\eta_{\text {dirt }}$, [9] will be considered to obtain the converted AC power from DC current and voltage using,

$$
P_{a c}=\left(V_{d c} \times I_{d c}\right) \times \eta_{i n v} \times \eta_{m m} \times \eta_{d i r t}
$$

\section{B. Battery Storage Device Model}

As discussed in Section II, the reduction of voltage rise by battery storage would depend on the amount of power being used in charging the battery. Battery power depends on battery voltage and charging current. Voltage during a charge or discharge operation is a non-linear function of the State of Charge (SoC) of the battery, as shown in Fig. 4 [10], for a typical charging and discharging characteristic of lead-acid 
batteries.

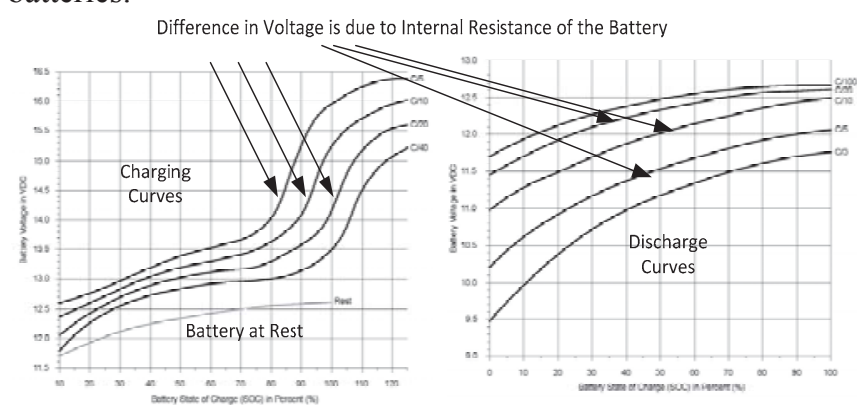

Fig. 4. Charge and discharge characteristic of a typical battery storage unit

From Fig. 4, it is also evident that voltages at different rates of charging and discharging are also different; this is due to internal resistance of the battery [9]. The differences in voltages are not uniform for the whole range of $\mathrm{SoC}$, as the internal resistance is also a non-linear function if the SoC [11]. When the battery is at rest, that is, no current flow takes place, the voltage becomes lower [10]. Polynomial interpolation technique applied in [12] to model the discharge curves of the batteries will be used in this paper. For a given state of charge (SoC), the voltage level when charging is different to that when discharging as shown in Fig. 4. This is due to the fact that some energy used to charge the battery is not recovered when the battery is discharged [13]. This will be considered in modeling the charge and discharge profiles of the battery. The charge and discharge profiles will be interpolated using polynomial functions.

The charging power of the battery, $P_{c h g}$, can be obtained from the battery voltage during the charging operation, $V_{c h}$, and the charging current $I_{c h g}$ as follows:

$$
P_{\text {chg }}=V_{\text {chg }} I_{\text {chg }}
$$

where: $I_{c h g}$ is obtained from the charging rate such as $\mathrm{C} / 5$, $\mathrm{C} / 10, \mathrm{C} / 20$ etc. and

$V_{c h g}$ is obtained from the SoC of the battery during charging cycle using the polynomial interpolation function given below:

$V_{\text {chg }}=K_{1} x^{4}+K_{2} x^{3}+K_{3} x^{2}+K_{4} x+K_{5}$

where: $K_{1}, K_{2}, K_{3}, K_{4}$, and $K_{5}$ are the coefficients of the polynomial of the charging voltage expression and $x$ denotes the charging state, SoC.

$\mathrm{SoC}$ can be found from the previous charging state, the present charging current, and the time interval between previous and present charging state as shown below,

$$
\operatorname{SoC}(t+\Delta t)=\operatorname{SoC}(t)+I_{\text {chg }} \Delta t
$$

Charging can be accomplished at different charging rates; a matrix representation of the polynomial functions of charging voltages is therefore convenient, as shown in (8) for $n$ number of charging rates.

The discharge voltage can be obtained from a similar polynomial function and the discharge power is obtained by multiplying the discharge voltage with the discharge current as shown in (5).

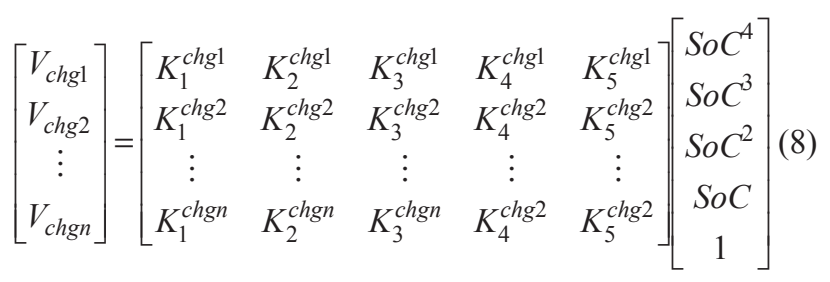

\section{Control of Charging and Discharging Operation Under Case Study}

The charging of the storage devices will take place in and around the noon period when the generation from PV will be higher than the loads. The PV system will monitor the voltage at the PCC and whenever this voltage is found above a set point and reverse power flow is detected at PCC, the system will command the charge controller to start the battery charging. It is assumed that initially the battery $\mathrm{SoC}$ is at a fixed level. As long as the voltage remains higher than the set point at the PCC, charging will continue until the $\mathrm{SoC}$ reaches a threshold level, to avoid overcharging. For a given storage capacity of the battery, the rate of charging is to be selected such that the battery capacity can be effectively used to reduce the voltage rise and also can be charged up to a substantial level to support the load when it is needed. For instance, if the charging rate is too high, the battery SoC may be near its overcharging limit earlier than the expected time, and may not be able to charge any more. This would bring back the voltage rise problem in the feeder. On the other hand, if the rate is too low, the battery may not be charged up to a level by which it can be used for a reasonable amount of peak shaving.

Discharging of the battery will be performed to shave the evening peak load when no or low PV generation is present. Discharge will commence when voltage falls below a threshold. The duration of the peak load support will depend on the amount of the stored energy in the battery. A rough estimate of this duration could be found by equating the amount of stored energy with the amount of energy required in the interval of the evening peak, where the battery will discharge. For example, using a discharge curve in Fig. 4, if $S_{o} C_{m}$ is the maximum attained state of charge prior to the start of the evening peak and $D o D$ is the maximum allowable depth of discharge, then the amount of energy available for discharge, $D E_{b a t}$, can be approximately obtained using,

$$
D E_{b a t}=\left(V_{1} S o C_{m}-V_{2} D o D\right) C_{b a t}
$$

where: $\quad V_{l}$ is the battery voltage $(\mathrm{V})$ at $S o C_{m}$ in pu

$V_{2}$ is the battery voltage (V) at $\mathrm{DoD}$ in pu

$C_{b a t}$ is the capacity of the battery in A-h

Since the energy for discharge is limited in nature, it is important to ensure that the energy can be used during the maximum peak. If the energy is used early, it is possible that the battery is already close to its maximum depth of discharge at the peak period, when it is most needed. To make effective use of the available stored energy in the battery, it will be discharged in an interval of time that includes the maximum evening peak. The amount of energy under the peak portion of the forecasted load curve within an interval $\left\{t_{1}, t_{2}\right\}, E P_{t 122}$, is given by, 


$$
E P_{t 1 t 2}=\int_{t 1}^{t 2} D(t) d t
$$

where, $D(t)$ represents the load curve.

The interval of the evening peak where the stored energy in the battery will be discharged to shave the peak load can be approximately obtained by selecting $\left\{t_{1}, t_{2}\right\}$ in (10) iteratively (starting from a small value and the increasing slowly) until $D E_{\text {bat }}$ is nearly equal to $E P_{t 1 t 2}$.

\section{CASE STUdies}

The modeling techniques and the control strategies of the storage integrated rooftop PV systems discussed in Section III will be applied on test distribution feeders. Network analysis will be performed using three phase four wire power flow approach based on current mismatch variant of the NewtonRaphson power flow algorithm [14].

Battery storage of $12 \mathrm{~V}, 250$ Ah will be integrated with each of the rooftop PV units in the feeder. Manufacturer provided charging and discharging curves of $12 \mathrm{~V}$ lead-acid batteries available in [9-11] will be interpolated using a MATLAB function based on least-square method; the curves thus obtained are shown in Fig. 5.

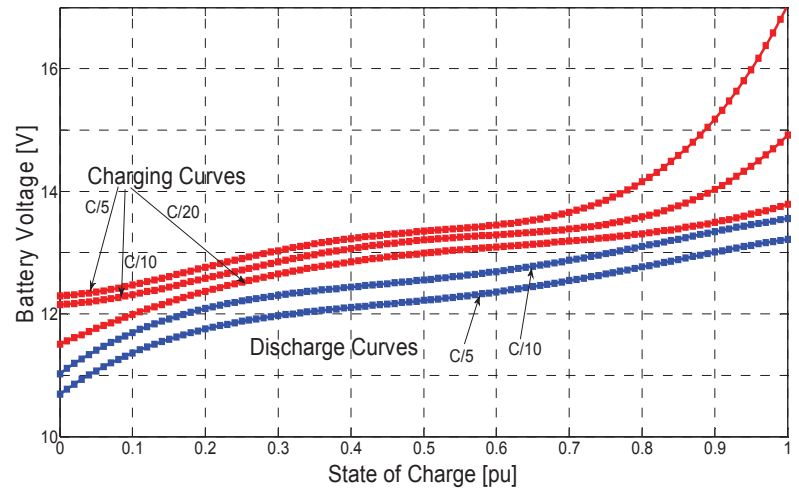

Fig. 5. Interpolated charge and discharge curves of a $12 \mathrm{~V}$ lead acid battery at different charging at discharging rates

\section{A. Study on a test LV feeder}

The control of charging and discharging operation discussed above will be applied to a simple three phase four wire test feeder shown in Fig. 6. The LV section of this test feeder is ideally similar to the LV feeders in Australian distribution networks. Typical electric appliances used in residential households were used to model the aggregate loads at the different phases of the test feeder. The PV inverter sizes at the residential households were limited within a range of $2-$ $4 \mathrm{~kW}$. PV penetration at a given time instant was defined as the ratio of the actual PV output at any PCC to the actual active power load at the time instant considered.

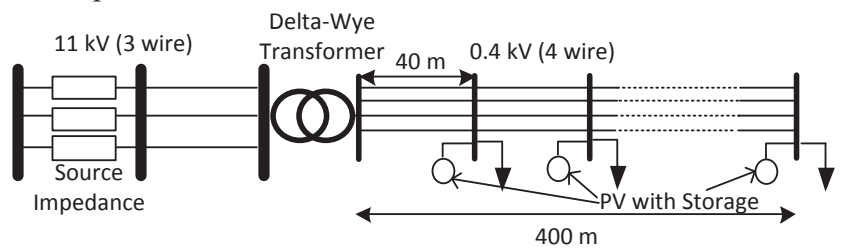

Fig. 6. Simple LV test feeder
Voltage profiles resulting from the application of storage is shown in Fig. 7 for the bus at the end of the feeder where the change is more visible due to lower short circuit strength. At about $9 \mathrm{am}$, the overvoltage set point is crossed and the net exchange of power is now positive with a PV penetration of $111 \%$ (i.e. with a PV output of $1.73 \mathrm{~kW}$ while serving a load of $1.55 \mathrm{~kW})$. This excess power is used to charge the battery; the battery power is shown in Fig. 8. At midday the PV power reaches approximately $2.93 \mathrm{~kW}$ and load is about $1.65 \mathrm{~kW}$ resulting to the increase in PV penetration to $177 \%$. For $\mathrm{C} / 20$ charging rate, the charging continues up to about $3 \mathrm{pm}$ when the voltage drops below the threshold value. Fig. 9 shows that at this charging rate the battery capacity at $3 \mathrm{pm}$ is not fully charged yet $(\mathrm{SoC}=0.74)$. If the charging rate is increased to $\mathrm{C} / 10$, the reduction in the voltage rise is higher, as shown in Fig. 7, due to higher amount of power being consumed by the battery during the charging operation, as shown in Fig. 8. The SoC of the battery reaches at 0.95 at about $2 \mathrm{pm}$, which is the assumed full level of the battery, as shown in Fig. 9 and the voltage rises above the threshold at this time. This means that the storage has not been effectively used to take advantage of the full duration of the PV generation, causing a period when the voltage rises above the threshold. Using the forecasted duration of the PV generation, some intelligent control can be devised to determine the correct charging rate of the battery to ensure that the PV is fully charged only when the voltage drops below the threshold value, and hence less amount of voltage rise will be experienced by the feeder. Fig. 7 shows such a scenario can be approximately achieved by setting the charging rate to $\mathrm{C} / 13$. The storage stops charging at about 3 $\mathrm{pm}$, when the PV penetration was about $106 \%$ with a PV output of $1.63 \mathrm{~kW}$ and a load of $1.53 \mathrm{~kW}$.

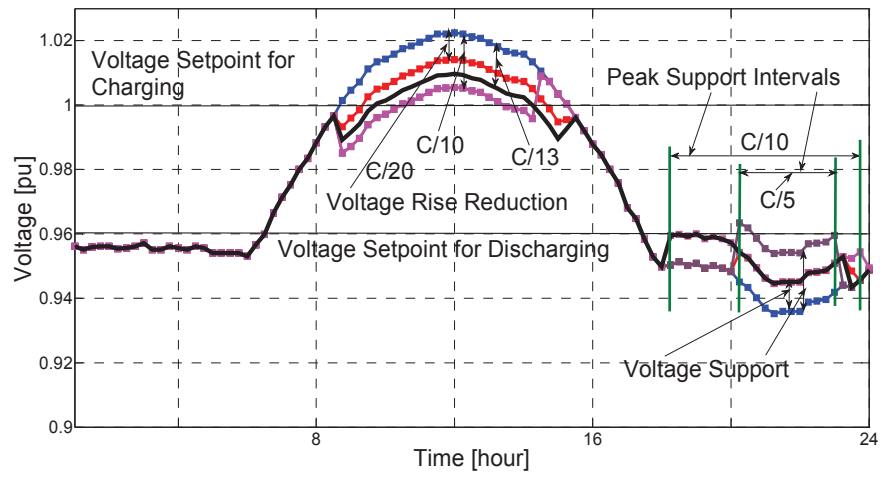

Fig. 7. Voltage rise reduction and voltage support by storage application in a simple three phase LV feeder

With the slow charging rate of $\mathrm{C} / 20$, the battery SoC reaches up to $74 \%$ of the capacity; this stored energy supports the evening peak for an interval of about 4 hours at $\mathrm{C} / 10$ discharge rate. This is shown as voltage improvement in Fig. 7 and power import reduction from the feeder in Fig. 8. With the faster $\mathrm{C} / 10$ charging rate, the battery SoC reaches up to its set overcharging limit of $95 \%$ and more energy is available for evening support. If the discharge rate is set to a higher level at $\mathrm{C} / 5$, the energy depletes in a shorter time of about 3 hours, however, with a larger import reduction at the peak load 
(higher tariff period) as shown in Fig. 8. For the slower $\mathrm{C} / 20$ discharge rate, the support can be provided for a longer duration of about 6 hours, until the minimum SoC is reached. Although maybe not all of the period has the higher tariff at the peak load, a more intelligent control could be devised to ensure that the maximum economic benefit can be achieved by integrating the charging and discharging control strategy with the electricity tariff.

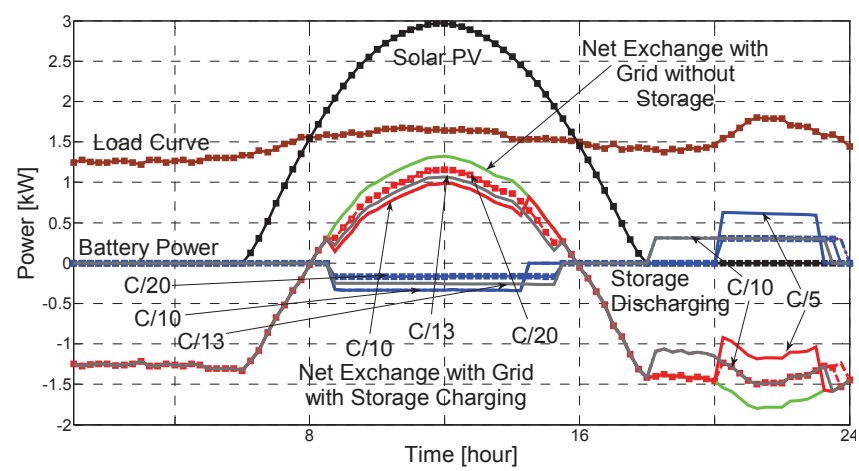

Fig. 8. Variation of levels of net power export/import with grid and battery power in relation to the load curve and solar PV generation

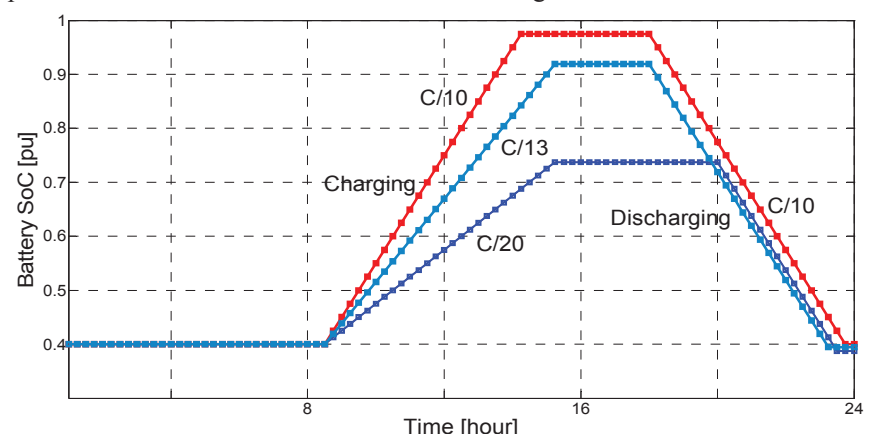

Fig. 9. State of charge of the battery with different charging and discharging rates

\section{B. Study on an Australian LV Feeder}

Practical distribution feeders would consist of unbalanced loads and line impedances. Patterns of load variation and PV generation would also be different from phase to phase. A model of an Australian LV distribution feeder in Western Sydney, New South Wales, was used to investigate the applicability of the proposed voltage rise mitigation strategy. A schematic diagram of the LV feeder is shown in Fig. 10 and the feeder data used for analysis are presented in Table I.

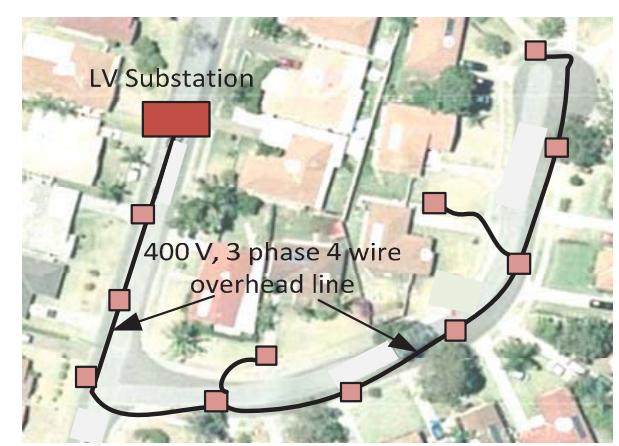

Fig. 10. A practical LV distribution feeder in Australia
TABLE I

DATA USED SimUlation OF THE AUSTRALIAN LV FEEDER

\begin{tabular}{|c|c|}
\hline Feeder Length (metre) & 350 \\
\hline Pole to Pole Distance (metre) & $30-40$ \\
\hline Conductor & $7 / 3.75 \mathrm{AAC}$ \\
\hline MV/LV Transformer Size & $160 \mathrm{kVA}$ \\
\hline PV Size (kW) & $2-4 \mathrm{~kW}$ \\
\hline PV Module Manufacturer & Kyocera \\
\hline Inverter Manufacturer & SMA Sunnyboy \\
\hline Battery Storage Model & $\begin{array}{l}\text { Lead-acid } \\
\text { Trojan L-16W }\end{array}$ \\
\hline Battery Storage Voltage (V) & 12 \\
\hline Battery Storage Capacity (Ah) & 250 \\
\hline
\end{tabular}

Fig. 11 shows the three phase voltage profiles at the end of the feeder with (solid lines) and without (dotted lines) the effect of storage. The charging rate was selected such that the storage can absorb surplus power from PV for nearly the entire period of overvoltage. Similarly, the discharging rate and interval was set such that the evening peak load can be reduced in the period of maximum peak when the support is most essential. Fig. 12 shows the corresponding power levels in three phases; it is observed that with storage, less amount of power is being injected into the feeder during noon, and less amount of power is being imported from the feeder in the evening.
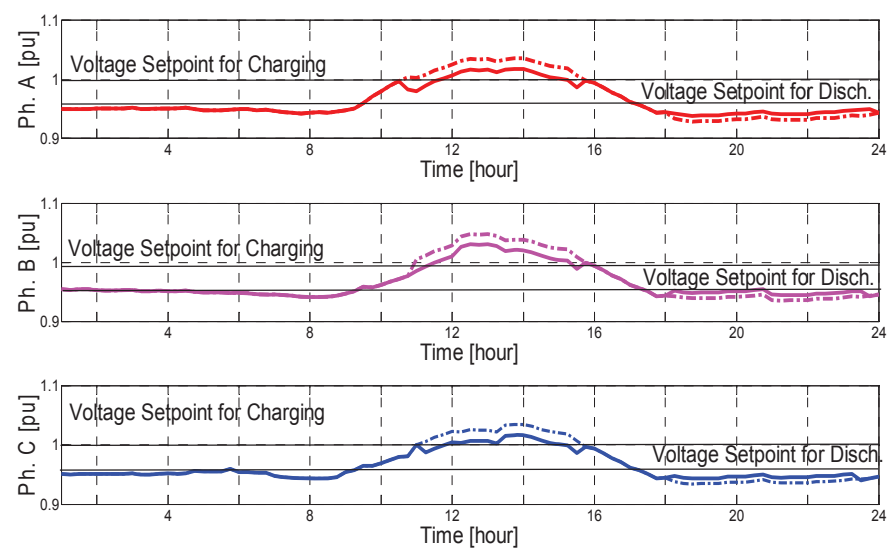

Fig. 11. Voltage rise reduction and voltage support by storage application in a simple three phase LV feeder
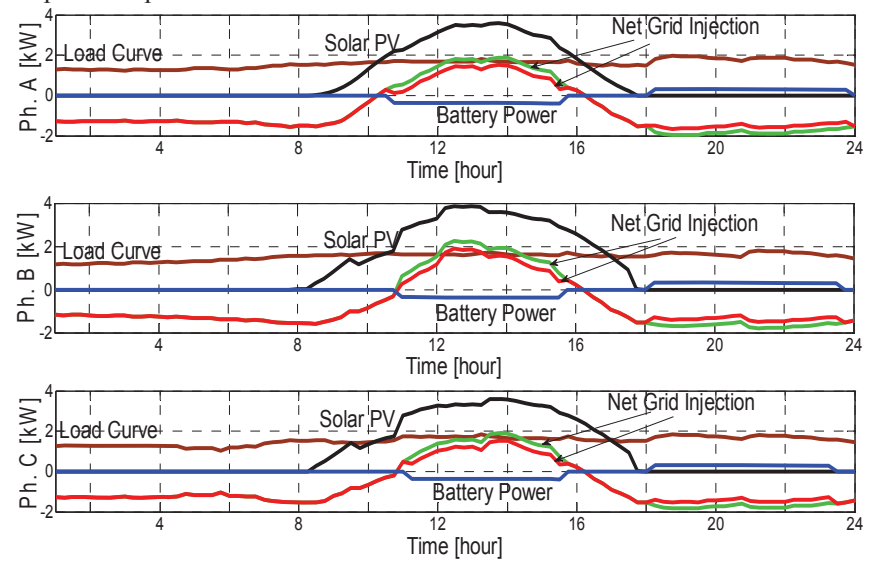

Fig. 12. Variation of levels of net power export/import with grid and battery power in relation to the load curve and solar PV generation

The batteries are charged up to their maximum SoC close to the end of the voltage rise period as shown in Fig. 13, and 
also discharged to maximum allowable $\mathrm{DoD}(40 \%)$ at the end of the evening peak.
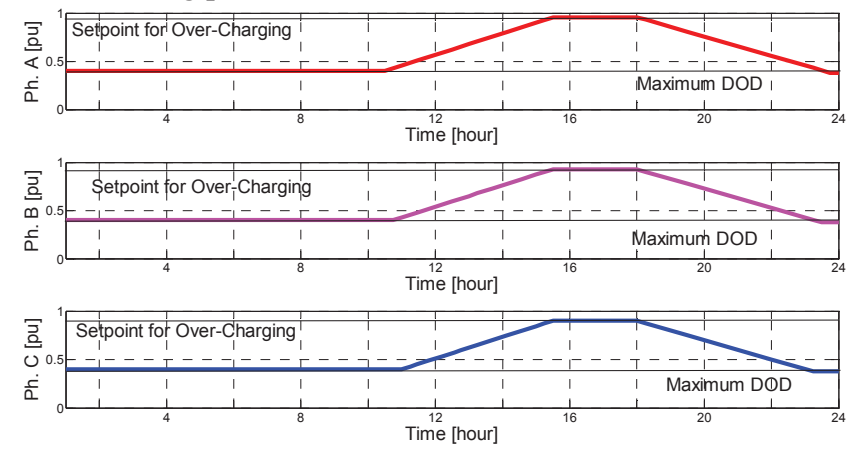

Fig. 13. State of charge of the batteries

To test the developed models and control algorithms in a variable PV generation environment, a practical solar PV output profile obtained from the Renewable Energy Integration Facility at CSIRO Energy Technology in Australia was used. The PV output was distorted by cloud passing effects. Fig. 14 shows the voltage rise mitigating effect of storage system. The proposed algorithm will operate the storage in charging mode only when the voltage rise is higher than the voltage setpoint; the storage will stop charging when the voltage drops below the charging threshold and enough surplus power is not available (shown in Fig. 15). Fluctuation in the battery power is also observed in Fig. 15 that indicates the storage device stops charging in the periods of reduced output of solar PV caused by cloud passing impacts. It is to be noted that if the charging is not stopped, the power for battery charging would be taken from the grid, which would incur additional electricity cost to the customers. The SoC of the battery in variable PV production environment is shown in Fig. 16. In accordance with the battery power profile, the SoC remains unchanged during the periods when the battery power level was zero. Due to this reason, the SoC level did not reach the desired $95 \%$ level of the full capacity with the charging rate applied.

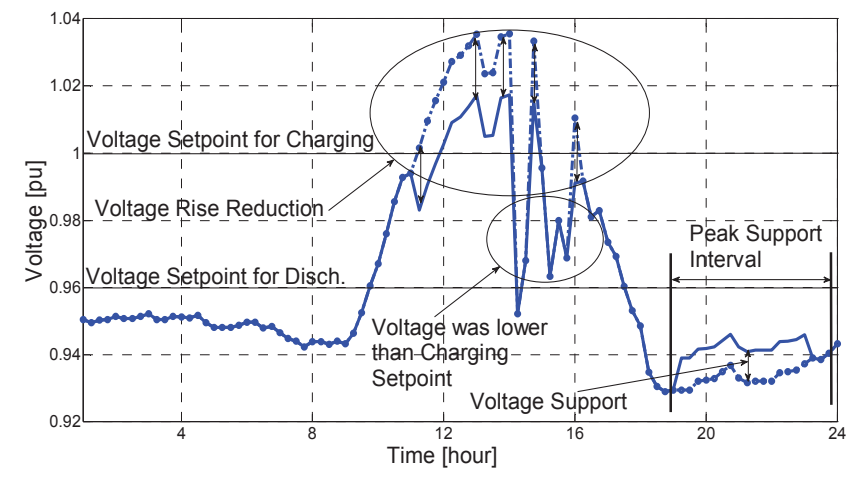

Fig. 14. Voltage rise mitigation with variable PV output

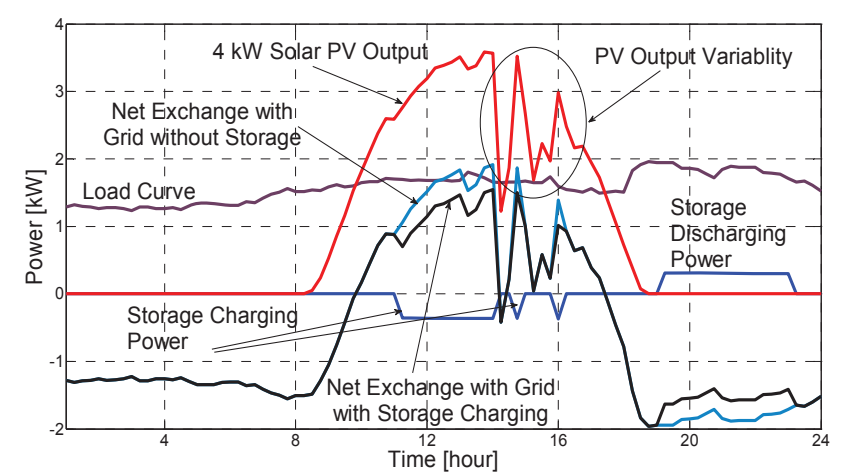

Fig. 15. Variation of levels of net power export/import with grid and battery power in relation to the load curve and variable solar PV generation

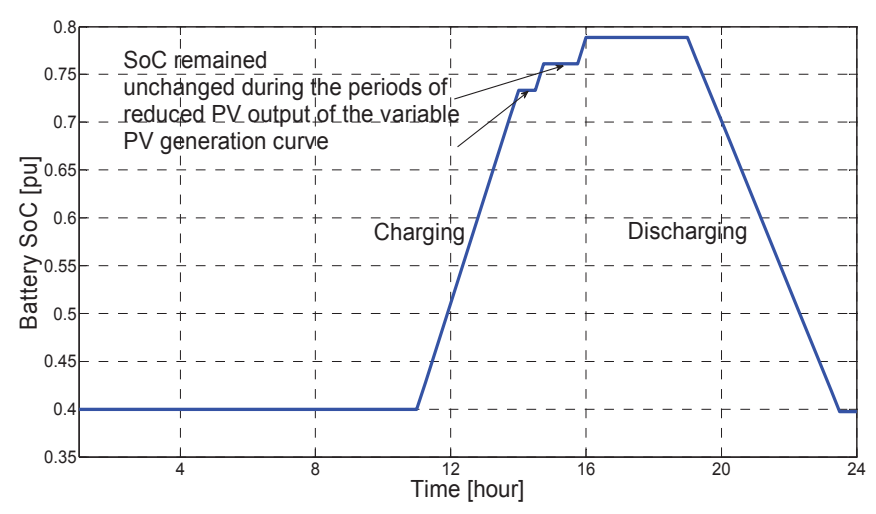

Fig. 16. State of charge of the battery with variable PV generation

\section{CONCLUSION}

The application of energy storage for mitigation of voltage rise problem caused by rooftop solar PV has been presented. The excess amount of power from the PV array at noontime, when PV generation is at peak level, can create voltage rise in the feeder. To mitigate the voltage rise problems, the paper proposes to utilize the surplus power to charge distributed battery storage devices to reduce the amount of active power injected into the grid. Realistic battery models incorporating the non-linear charging and discharging characteristics are used. An intelligent control strategy for charging and discharging operation is developed to make effective use of the available battery capacity. Simulation results from a realistic distribution feeder show that for a given capacity of the battery, the charging and discharging rate needs to be properly selected to ensure that battery is effectively used for the entire duration of the day.

\section{ACKNOWLEDGMENT}

This work is supported by the Australian Research Council (ARC) and Essential Energy Linkage Grant, LP100100618. The authors gratefully acknowledge the support and cooperation of Essential Energy, Endeavour Energy and CSIRO Energy Technology for providing practical system information and data for this research. 


\section{REFERENCES}

[1] A. Canova, L. Giaccone, F. Spertino, and M. Tartaglia, "Electrical Impact of Photovoltaic Plant in Distributed Network," Industry Applications, IEEE Transactions on, vol. 45, pp. 341-347, 2009.

[2] M. Thomson and D. G. Infield, "Network Power-Flow Analysis for a High Penetration of Distributed Generation," Power Systems, IEEE Transactions on, vol. 22, pp. 1157-1162, 2007.

[3] R. A. Walling, R. Saint, R. C. Dugan, J. Burke, and L. A. Kojovic, "Summary of Distributed Resources Impact on Power Delivery Systems," Power Delivery, IEEE Transactions on, vol. 23, pp. 1636-1644, 2008.

[4] E. Demirok, D. Sera, R. Teodorescu, P. Rodriguez, and U. Borup, "Clustered PV inverters in LV networks: An overview of impacts and comparison of voltage control strategies," in Electrical Power \& Energy Conference (EPEC), 2009 IEEE, 2009, pp. 1-6.

[5] Y. Liu, J. Bebic, B. Kroposki, J. de Bedout, and W. Ren, "Distribution System Voltage Performance Analysis for High-Penetration PV," in Energy 2030 Conference, 2008. ENERGY 2008. IEEE, 2008, pp. 1-8.

[6] P. M. S. Carvalho, P. F. Correia, and L. A. F. Ferreira, "Distributed Reactive Power Generation Control for Voltage Rise Mitigation in Distribution Networks," Power Systems, IEEE Transactions on, vol. 23, pp. 766-772, 2008.

[7] Y. Ueda, K. Kurokawa, T. Tanabe, K. Kitamura, K. Akanuma, M. Yokota, and H. Sugihara, "Study on the over voltage problem and battery operation for grid-connected residential PV systems," 2007.

[8] M. G. Villalva, J. R. Gazoli, and E. R. Filho, "Comprehensive Approach to Modeling and Simulation of Photovoltaic Arrays," Power Electronics, IEEE Transactions on, vol. 24, pp. 1198-1208, 2009.

[9] G. M. Masters and I. ebrary, "Renewable and efficient electric power systems," 2004.

[10]R. Perez, "Lead-acid battery state of charge vs. voltage," Home Power, vol. 36, pp. 66-69, 1993.

[11]N. K. Medora and A. Kusko, "Dynamic Battery Modeling of Lead-Acid Batteries using Manufacturers' Data," in Telecommunications Conference, 2005. INTELEC '05. Twenty-Seventh International, 2005, pp. 227-232.

[12]I. Papic, "Simulation model for discharging a lead-acid battery energy storage system for load leveling," Energy Conversion, IEEE Transactions on, vol. 21, pp. 608-615, 2006.

[13]R. Rynkiewicz, "Discharge and charge modeling of lead acid batteries," in Applied Power Electronics Conference and Exposition, 1999. APEC '99. Fourteenth Annual, 1999, pp. 707-710 vol.2.

[14]D. R. R. Penido, L. R. de Araujo, S. Carneiro, J. L. R. Pereira, and P. A N. Garcia, "Three-Phase Power Flow Based on Four-Conductor Current Injection Method for Unbalanced Distribution Networks," Power Systems, IEEE Transactions on, vol. 23, pp. 494-503, 2008.

\section{BIOGRAPHIES}

M. J. E. Alam (Grad. Std. M'10) received B.Sc. and M.Sc. Degree in Electrical and Electronic Engineering Bangladesh University of Engineering and Technology, Dhaka, Bangladesh, in 2005 and 2009, respectively. At present he is conducting $\mathrm{PhD}$ research at the University of Wollongong, Wollongong, Australia. Prior to starting PhD studies, he has been involved with power industry in Bangladesh for 4.5 years.

K. M. Muttaqi (M'01, SM'05) received the Ph.D. degree from Multimedia University, Malaysia, in 2001. Currently, he is an Associate Professor at the School of Electrical, Computer, and Telecommunications Engineering, University of Wollongong, Wollongong, Australia. He was associated with the University of Tasmania, Australia as a Research Fellow/Lecturer/Senior Lecturer from 2002 to 2007, and with the Queensland University of Technology, Australia as a Research Fellow from 2000 to 2002. Previously, he also worked for Multimedia University as a Lecturer for three years.

Danny Sutanto (SM'89) obtained his BEng. (Hons) and $\mathrm{PhD}$ from the University of Western Australia. He is presently the Professor of Power Engineering at the University of Wollongong, Australia. His research interests include power system planning, analysis and harmonics, FACTS and Battery Energy Storage systems. He is a Senior Member of IEEE. 